\title{
RETICULATE MELANISM IN CANADIAN WESTERN PAINTED TURTLES
}

FREDERICK W. SCHUELER, Herpetology Section, National Museum of Natural Sciences, National Museums of Canada, Ottawa, Ontario. K1A OM8

In 1969 H. M. Smith, D. C. Kritsky, and R. C. Holland reported Painted Turtles (Chrysemys picta) from North Dakota which had an intricate pattern of narrow dark markings on the carapace, which they called 'reticulate melanism'. ${ }^{20}$ They only saw this pattern on some large adults in the populations they observed, and the two melanic individuals they examined were both males. The colour pattern was similar to that of some males of Antillean sliders, especially the Cuban Chrysemys decussata, but different from that seen on any other turtle. ${ }^{1} \mathrm{C} . \mathrm{H}$. Ernst and R. W. Barbour have since asserted that "reticulate melanism commonly occurs in some populations of Chrysemys picta bellii" (caption of their Figure 124) the
Western Painted Turtle and R. Conant has mentioned that reticulate melanism is confined to adult males. ${ }^{54} \mathrm{C}$. $\mathrm{H}$. Ernst and E. M. Ernst found it on both sexes in southwestern Minnesota, while R. D. MacCulloch found it only on males in southern Saskatchewan. ${ }^{112}$

This paper describes the widespread occurrence of reticulate melanism in western Canada, confirms that it is largely confined to adult males, and suggests hypotheses about its adaptive value.

\section{Materials}

I examined specimens in the collections of the National Museum of Natural Sciences, National Museums of Canada

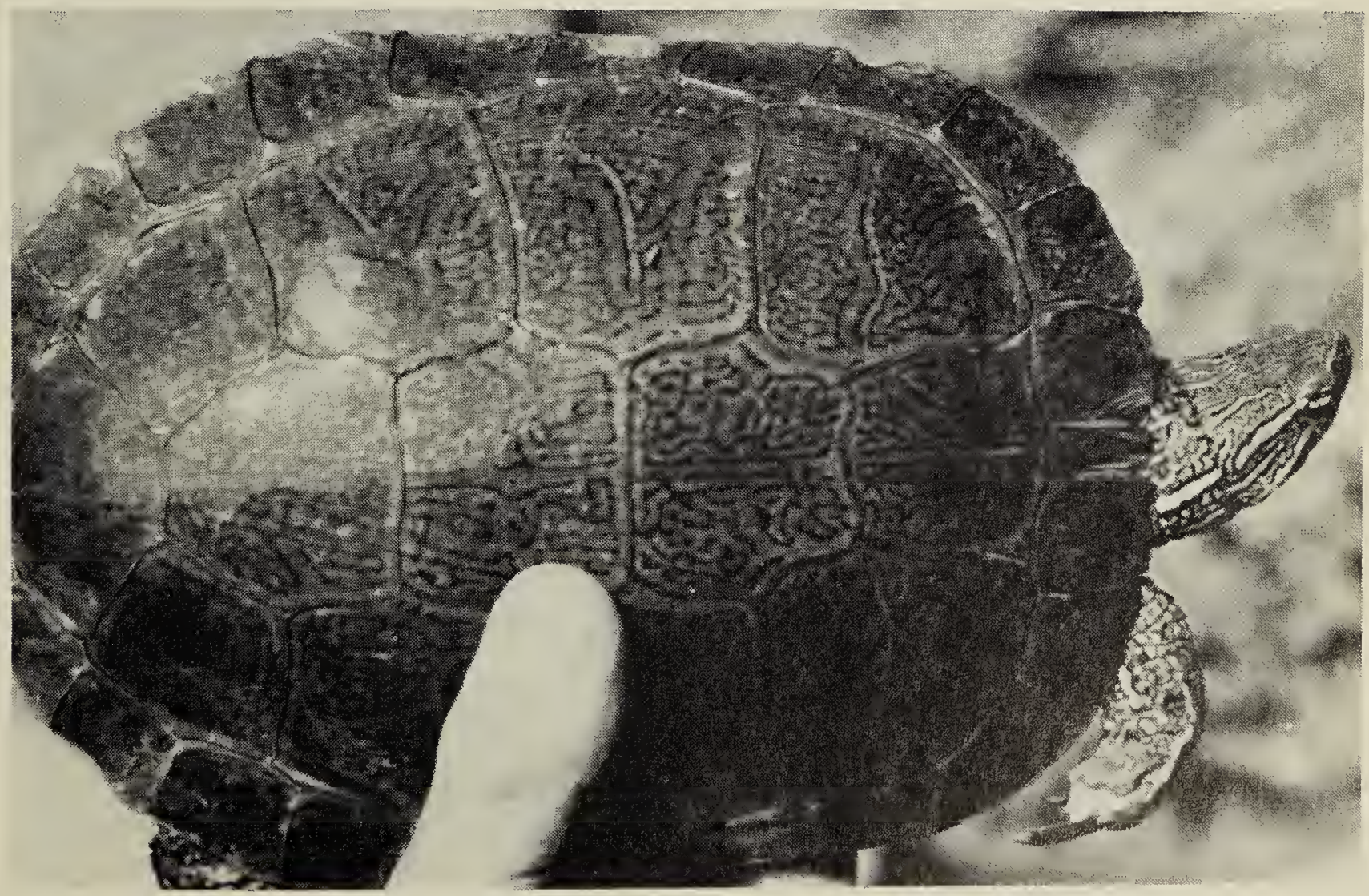

Figure 1. Reticulately melanic male Chrysemys picta from Qu'Appelle River, Saskatchewan. Plastron $190 \mathrm{~mm}$.

R. D. MacCulloch 
(NMC), the Royal Ontario Museum (ROM), and the American Museum of Natural History. R. W. Campbell and N. Panter kindly examined the collections of the British Columbia Provincial Museum and the University of Alberta Museum of Zoology for me, and Ross MacCulloch of the Saskatchewan Museum of Natural History has allowed me to use his measurements, observations, and photographs.

\section{Methods}

I measured the size of specimens by plastron length and identified adult males by their long foreclaws and preanal tail length. I noted the intensity of reticulate melanic markings, and assessed the extent of reticulate melanism by the number of major laminae (the horny plates of the shell, excluding the marginals and nuchal around the edge of the shell) with reticulate markings.

I use the name "Chrysemys picta belli" in its usual sense, to denote western populations of Chrysemys picta with light carapace colours, extensive markings on the plastron, and a network of light markings on the carapace. ${ }^{23}$

\section{Distribution in Canada}

All localities where reticulate melanism has been found are mapped in Figure 2. Well developed reticulate melanism is largely restricted to large adult males. All of the large ROM and NMC specimens from western Ontario populations of $C$. $p$. belli are female. A reticulately melanic male was examined by F. D. Ross, Aleta Karstad, and me on a dock at Sioux Narrows, Ontario, in July 1976, but it was so tame that it may have been released by one of the many Manitobans who vacation there.

All large (plastron greater than 150 $\mathrm{mm}$ ) male specimens I examined from Manitoba and Saskatchewan are reticulately melanic, and one female from Lake Sewell, Manitoba (NMC 8618-11) has a blurred reticulum. The male specimens are from Whiteshell Provincial Park (two specimens), Carberry (one), and Lake Sewell (nine), in Manitoba, and "Wood Creek (3.5 mi. northeast of Wood Mountain), Saskatchewan" (one specimen, NMC 1549, 22 July 1929; evidently Wood Mountain Creek). Ross MacCulloch has found melanic males in the Qu'Appelle River



Figure 2. Localities where reticulate melanism has been found in Chrysemys picta. Localities are listed in the text. The heavy line is the northern limit of the range of the species. A circle around Pender Harbour and Texada Island is darkened. 
between Craven and Lumsden (Figure 1), in Rinfret Creek $5 \mathrm{~km} \mathrm{SE}$ of Weyburn, and Wascana Lake (where some turtles are introduced) in Regina, Saskatchewan (in litt.). There are no large males or reticulate melanism among the three specimens from the Milk River of Alberta (R. Panter, in litt.).

Some adult males from the interior of British Columbia are reticulately melanic. T. L. Thacker may have been the first to collect reticulately melanic Chrysemys picta (NMC 965) at Vaseux Lake in June 1922, but in his account of these turtles he does not mention this colour pattern. ${ }^{21}$ G. P. Holland did not record reticulate melanism in his study of variation in coloration in British Columbia C. picta, but he only examined eight adult males. ${ }^{11}$ There are NMC specimens of reticulately melanic males from Vaseux Lake (three specimens), Osoyoos Lake (two), and Genier Lake (three). In the sample from Genier Lake there are eight females which have faint or speckled melanism; this is also present on a $196 \mathrm{~mm}$ female from $1 \mathrm{~km}$ N. of Peachland, B.C. (NMC 17407). There is a large nonmelanic male from Osoyoos Lake in the B.C. Provincial Museum (No. 597; $162 \mathrm{~mm}$ ). In ROM collections made in 1928 and NMC collections made in 1963 from small lakes in a valley west of Vaseux Lake the males are not reticulated (NMC 7213, Mahoney Lake, $165 \mathrm{~mm}$; ROM 2582-2 \& 3, Green Lake, 164, $171 \mathrm{~mm}$ carapace length), and all of the specimens have a dusky blackish colour in preservative rather than the brownish colour of most C. p. belli; some of the females are quite black (ROM 2580, 2585).

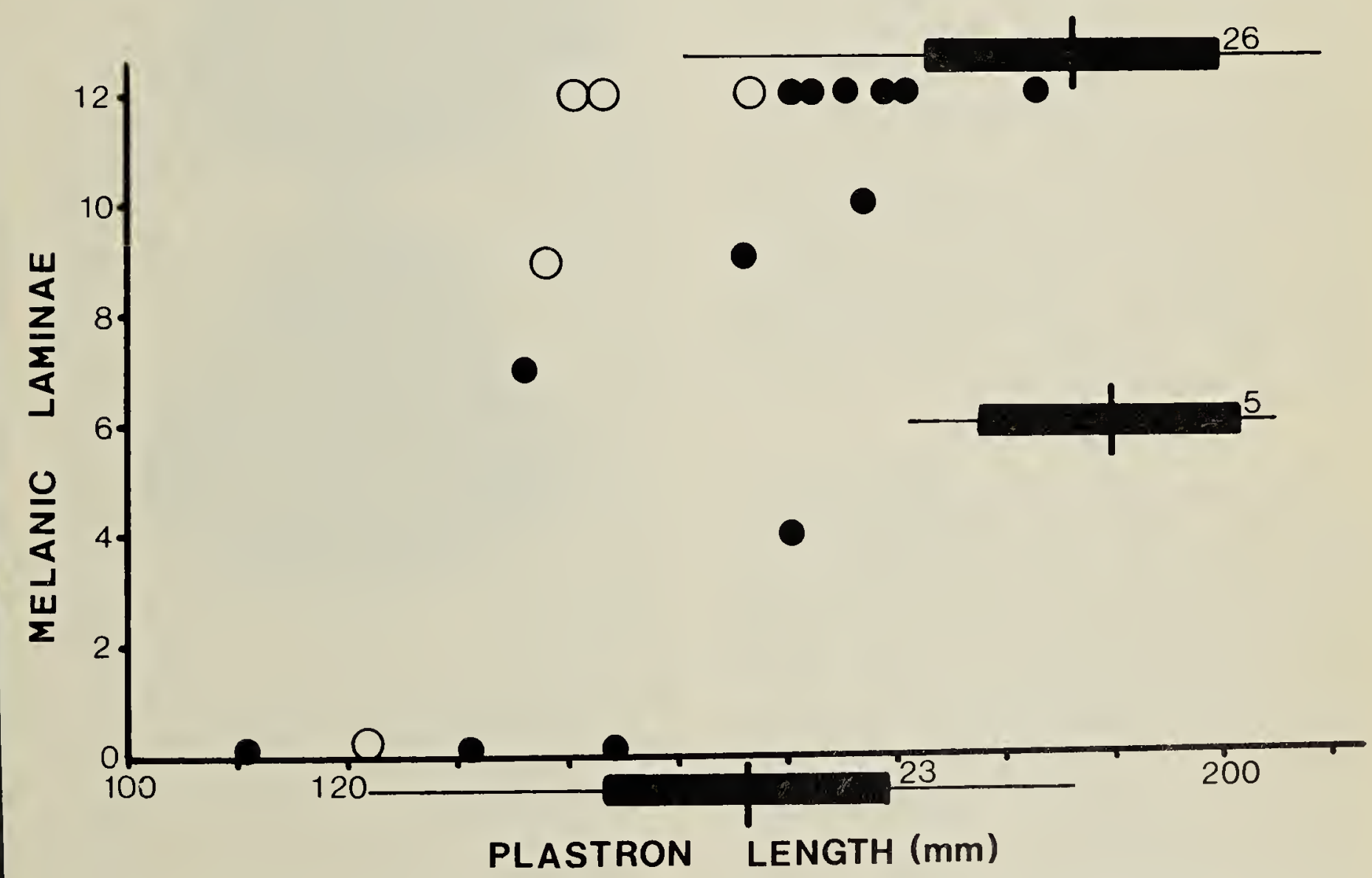

Figure 3. Reticulate melanism in relation to size in male Chrysemys picta. These are sexually mature specimens, as indicated by elongated foreclaws. Specimens from Lake Sewell, Man. are shown as dots, those from Vaseux Lake by circles. Bar diagrams show range, mean, \pm 2 standard deviations and sample size for specimens from MacCulloch's southern Saskatchewan sites; from the top down these were denoted as: "with reticulate melanism," "partial reticulate melanism," and "without reticulate melanism." 


\section{Development of melanization}

The following account is based on the assumption that less extensive melanic markings develop into more extensive patterns. The evidence for this is the larger size of completely melanic specimens (Figure 3 ); but some of the variation may really be individual variation in the final adult pattern. Unlike other coloration of $C$. picta the reticulate melanin is deposited in the horny laminae. ${ }^{20}$ These markings appear after the development of the long foreclaws characteristic of adult males in this species, at a plastron length of about 140-150 mm at Vaseux Lake and Lake Sewell and about $170 \mathrm{~mm}$ in the Qu'Appelle River and Rinfret Creek (Figure 3). Melanization apparently develops from the dark borders of the light lines that outline the edges of the laminae and form a network elsewhere on the shell. Early stages can be seen in small males such as NMC 8621 (144 $\mathrm{mm}$; Figure 4B). In this specimen many of the dark borders of the laminae are paralleled by another dark line which is separated from the border line by a gap of 2-4 $\mathrm{mm}$. There are flecks of dark pigment elsewhere on the shell, but none between the parallel dark lines. In other specimens with less prominent dark borders on the laminae the initial black markings develop separately as in NMC 8057 (Figure 4A).

The head pattern of melanic specimens is a mottled or reticulated pattern of dark markings rather than the normal striped pattern (Figure 5). This change is brought about by a breakdown in the dark interstripe areas and an expansion of the light stripes into the interstripe. All of the fully reticulate NMC and ROM specimens have this modified head pattern. I quantified the disruption of the striped pattern in two ways among the Lake Sewell specimens: the median dorsal head stripe is shorter on melanic specimens (those with more than eight laminae with reticulation) than on nonmelanic specimens (those with no

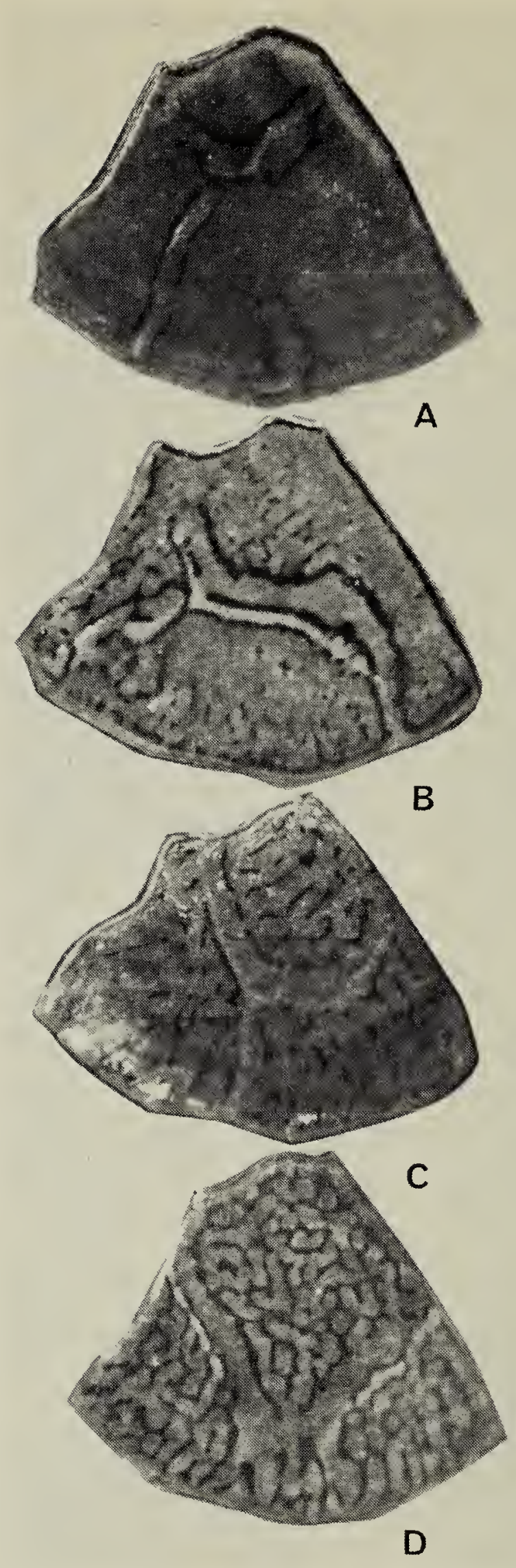

Figure 4. Reticulate melanism on the first left lateral carapacal lamina of male Chrysemys picta from Manitoba. A. NMC 8057, $136 \mathrm{~mm}, 7$ melanic laminae, $1 \mathrm{mi}(1.6 \mathrm{~km}) \mathrm{S}$ Bereton Lake, Whiteshell Park; B. NMC 8621, 144 $\mathrm{mm}, 12$ melanic laminae, Horseshoe Lake, S of Carberry; C. NMC 8622-3, $169 \mathrm{~mm}, 12$ reticulate laminae, Lake Sewell, E of Shilo; D. NMC 8614-4, 162 $\mathrm{mm}, 12$ reticulate laminae, Lake Sewell, E of Shilo. 


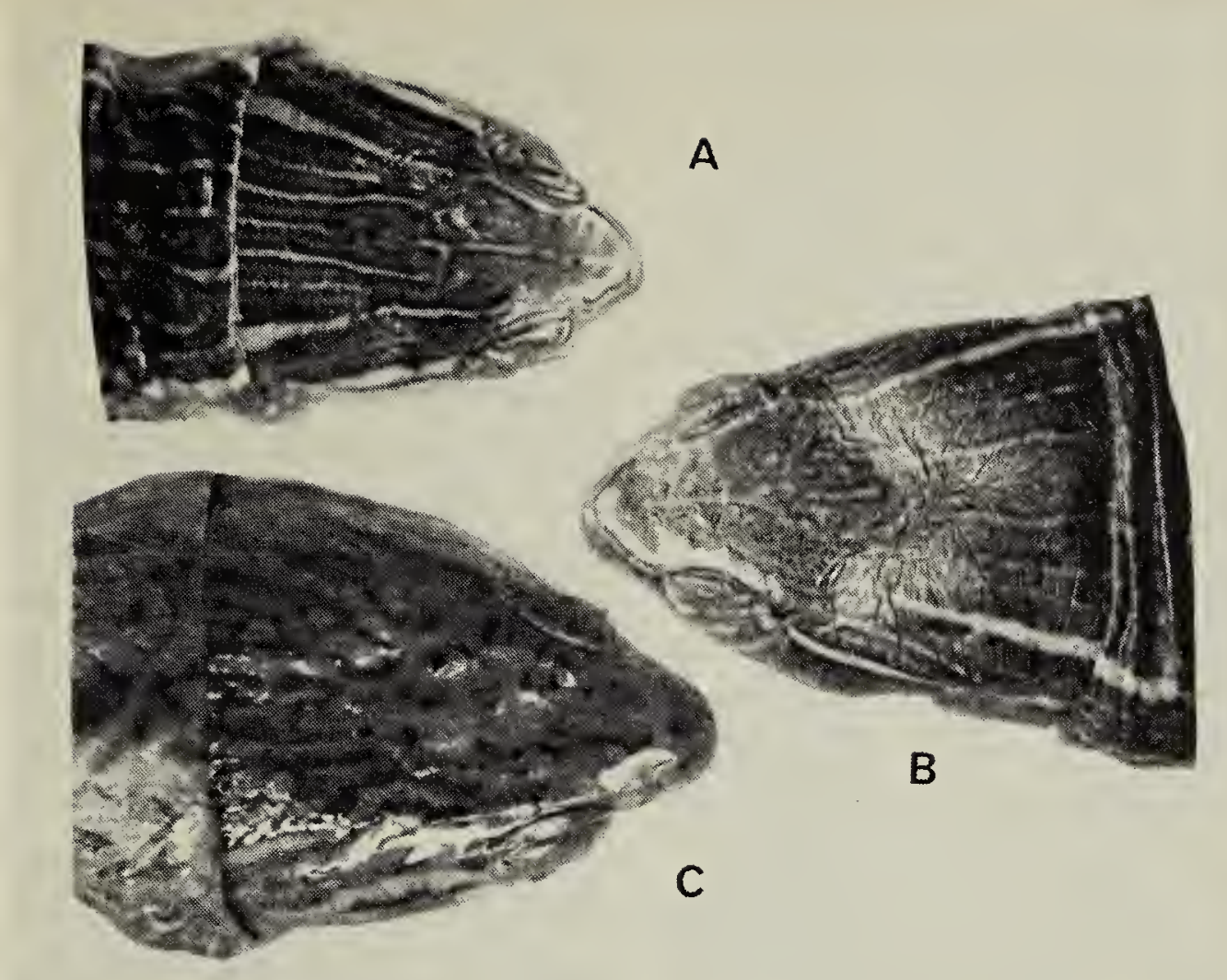

Figure 5. Heads of Chrysemys picta from Manitoba. A. NMC 8622-5, female, $131 \mathrm{~mm}$, no melanic laminae, Lake Sewell, E of Shilo; B. NMC 8057, male, $136 \mathrm{~mm}, 7$ melanic laminae, $1 \mathrm{mi}(1.6 \mathrm{~km}) \mathrm{S}$ Bereton Lake, Whiteshell Park; C. NMC 8622-4, male, $165 \mathrm{~mm}$, 12 reticulate laminae, Lake Sewell, $E$ of Shilo.

laminae with reticulation); of eight melanic specimens the median stripe extends beyond the narrowest point between the eyes on only one specimen, while it extends beyond this point on 16 of 19 nonmelanic specimens (of both sexes; $G=9.7, p<0.005$ ). In eight melanic specimens the average number of light dorsal longitudinal stripes on the head between the tympana of the ears was 2.37, while 18 nonmelanic specimens averaged 5.00 stripes ( $t=$ $4.12, p<0.001)$. In the southern Saskatchewan populations examined by MacCulloch this change is less marked (Figure 1), and "the mid-dorsal head stripe extends both anterior and posterior to the narrowest point between the orbits." (in litt., 29 Sept. 1981).

The striping of the legs and the plastral pattern seem unaffected by the melanism, though there may be minor quantitative differences.
Three of the eight lightly melanized females from Genier Lake have the median stripe reduced, but they average 3.8 stripes at the ears, compared with 4.0 for the two unmelanized males, and 2.3 for the three melanic males.

\section{Discussion}

Shell patterns like reticulate melanism are rare in turtles. In scanning several books of pictures of turtles I have found only one pattern that is much like it (beside the Antillean Chrysemys previously mentioned): a very lightly melanized Blanding's Turtle (Emydoidea blandingi; Pritchard, Figure on page 269). ${ }^{3}{ }^{17}$ Melanism is frequent in sliders of the Chrysemys scripta complex, but in populations of this species in the United States, at least, the melanism involves changes in the pattern of the plastron and blackening of the entire carapace and of the skin. 
which is not seen in C. picta..$^{3^{13}}$ In this species, as in C. picta, the smallest fully melanized individuals are about 130$150 \mathrm{~mm}$ in most populations, the melanin extends into the horny laminae, and melanization is more frequent or intense in males, though females are also often melanic. ${ }^{3} 513$ The tropical populations of C. scripta are extremely variable in colour pattern, and some seem to approach reticulate melanism, certainly the related Cuban Slider, C. decussata, has melanic males which are quite as reticulated as some $C$. picta belli. Melanization in this species evidently progresses both by the spread of dark pigment and by the lightening of already darkened areas, and the depigmented areas are a different colour from the unmodified areas. There is evidently geographic variation in
Cuba in the importance of melanin spread and depigmentation in the development of the reticulate pattern. The striped pattern of the head and limbs gives way to a dark reticulum in the melanic males. ${ }^{1}$

Male colour patterns differ from those of females in being blacker, more contrasting, or both in about 25 aquatic turtle species in which there is a difference (Table 1). Besides the species listed in the table, the sexes of the softshell turtles Trionyx ater and $T$. ferox differ in carapace pattern, but neither sex is clearly more contrasting. ${ }^{22}$ Males of the Asian river turtles Callagur borneoensis and Batagur baska are more different from each other and from the females during the breeding season, perhaps as a result of reproductive character dis-

Table 1. SEXUAL COLOUR DIFFERENCES IN AQUATIC TURTLES. ${ }^{1} 171422$

How males differ from females

Reticulate melanism

Black coloration

Black dorsal stripes

More distinct carapace pattern

(at least in some

populations)

More contrasting head pattern

Orange or red head colours
Species

Chrysemys picta belli

C. decussata

C. felis?

Chrysemys scripta

C. stejnegeri

C. terrapen

C. malonei

C. decorata

C. rubriventris

Batagur baska

Kachuga trivittata

Callagur borneoensis

Trionyx spiniferus

T. muticus

Kachuga kachuga

Kinosternon scorpioides

K. dunni

Dermatemys mawi

Podocnemis unifilis

$P$. erythrocephala

P. volgi

Phrynops dahli

Trionyx spiniferus emoryi

Callagur borneoensis

Kachuga kachuga 
placement. ${ }^{14}$ In two terrestrial tortoises (Geochelone elegans, Kinixys belliana) females are more contrastingly marked than males. ${ }^{17}$

There are about 170 species of freshwater aquatic turtles, so about $15 \%$ of them have sexual colour differences. ${ }^{17}$ This is certainly a lower proportion of differing species than occurs among birds or lizards, and higher than that among snakes or salamanders, or, perhaps, frogs or nonprimate mammals. Since the males are so often the more contrastingly patterned sex it is likely that the differences are due to sexual selection acting through female choice or male combat.

There is a possible adaptive function for reticulate melanism in Chrysemys picta related to each of the possible functions of animal coloration: concealment, communication, and solar thermoregulation. ${ }^{10}$ Such speculation is premature in terms of capability to test the hypotheses, but may suggest directions for future research.

\section{Concealment hypothesis.}

The suggestion that reticulate melanics are cryptic follows from the observation that similar reticulate patterns occur in prairie populations of the Northern Leopard Frog (Rana pipiens) and the Tiger Salamander (Ambystoma tigrinum). Several mottled or reticulate dorsal pattern variants of $R$. pipiens are sympatric with reticulately melanic Chrysemys picta on the northern Great Plains, ${ }^{19}$ and $A$. tigrinum from this area are more reticulated in pattern than those from elsewhere in the species' range (though with differing patterns which are the bases for $A$. $t$. diaboli and $A$. $t$. melanostictum). ${ }^{7}$ If such a pattern is particularly cryptic in prairie ponds it may allow turtles to approach prey or avoid detection by such predators as a $150 \mathrm{~mm}$ turtle may have. It is hard to see why only adult males should be melanic.

\section{Communication hypothesis.}

The function of the complex red, black, orange, and yellow colour patterns of Chrysemys picta is unknown, but at least the plastron colours may serve a communication function, since the plastron is not exposed to solar radiation or aerial predators and red and yellow are implausible as optimal concealment from aquatic predators. If the complex ventral pattern of C. p. belli serves some social function, then the repetition of a similar pattern on the dorsum may enhance the social status or courtship success of a male. The tendency for male aquatic turtles to be more contrastingly patterned suggests that such a pattern might be particularly advantageous to males.

\section{Energy coloration hypotheses.}

One hypothesis is borrowed from the studies of A. R. Gibson on the garter snake Thamnophis sirtalis at Long Point, Lake Erie, Ontario, where he could only account for the occurrence of an all-black morph by postulating that since male melanics absorbed more sunlight than the lighter-coloured striped morph, they were able to be more active, and thus had greater courtship success during the cool, early spring breeding season. ${ }^{8}{ }^{18} \mathrm{C}$. picta begins courtship at water temperatures as low as $10^{\circ} \mathrm{C}$ and if pale C. p. belli are energy-coloured (see Appendix), then in northern populations adult males that were darker might have higher body temperatures and greater activity and courtship success in the cold water of spring. This hypothesis has the advantage that the proposed adaptation benefits the northern adult males of a palecoloured race, so it is not necessary to explain why other C. picta are not reticulately melanic. The opposite possibility exists, however: perhaps 
the black markings, since they are in the horny laminae rather than beneath them as other markings are, serve to reradiate heat from the surface of the shell rather than allowing it to be trapped beneath the laminae where it would warm the turtle excessively. ${ }^{8}$ Perhaps the melanization of the carapace is even only a developmental side effect of the reduction of melanin on the head.

The occurrence of geographically adjacent dusky-melanic and reticulately-melanic populations of Chrysemys picta (Green Lake - Vaseux Lake and Pender Harbour - Texada Island; see Appendix) should allow field study of the ecological determinants of carapace colour of C. picta. The concealment hypothesis would be falisified if the bottom colours of the lakes do not parallel the colours of the turtles, and one could discriminate between different energy-coloration hypotheses by measuring radiation patterns of turtles of different colours and by observing their basking behaviour. ${ }^{16}$

\section{Acknowledgements}

I thank E. J. Crossman for access to the ROM specimens, Ross MacCulloch for the use of his data, and NSERC (then NRC) for support during the earlier years of this investigation, through their grant to J.D. Rising. Francis Cook collected the bulk of the NMC specimens which made this study possible, and I thank him for his wellversed criticism of the manuscript, and Francie Thompson for her thoughts on its intelligibility.

' BARBOUR, T., and A. CARR, Jr. 1940. Antillean terrapins. Bulletin, Museum of Comparative Zoology. 54:384-413.

${ }^{2}$ BLEAKNEY, J. S. 1958. Postglacial dispersal of the turtle Chrysemys picta. Herpetologica 14:101-104.

${ }^{3}$ CARR, A. 1952. Handbook of Turtles. Cornell University Press, Ithaca, New York. 542 pp.
${ }^{4}$ CONANT, R. 1975. A Field Guide to Reptiles and Amphibians of Eastern and Central North America. 2nd edition. Houghton Mifflin, Boston. 429 pp.

${ }^{5}$ ERNST, C. H., and R. W. BARBOUR. 1972. Turtles of the United States. University of Kentucky Press, Lexington. 347 pp.

${ }^{6}$ ERNST, C. H., and E. M. ERNST. 1973. Biology of Chrysemys picta bellii in southwestern Minnesota. Journal, Minnesota Academy of Sciences 38:77-80.

' GEHLBACH, F.R. 1967. Ambystoma tigrinum. Catalogue of American Amphibians and Reptiles 52:1-4.

${ }^{8}$ GIBSON, A.R. 1978. The ecological significance of a colour polymorphism in the Common Garter Snake, Thamnophis sirtalis. Canadian Journal of versity of Toronto. $434 \mathrm{pp}$. (Dissertation Abstracts International 39B:3190-3191)

${ }^{9}$ GIBSON, A. R., and J. B. FALLS. 1975. Evidence for multiple insemination in the Common Garter Snake, Thamnophis Sirtalis. Canadian Journal of Zoology 53:1362-1368.

${ }^{10}$ HAMILTON, W. J., III. 1973. Life's Color Code. McGraw-Hill, New York. 238 pp.

1 HOLLAND, G.P. 1937. Life history and distributional studies of Bell's Painted Terrapin, Chrysemys picta bellii (Gray). M.A. Thesis, University of British Columbia. $133 \mathrm{pp}$.

${ }^{12} \mathrm{MacCULLOCH}$, R. D. 1981. Variation in the shell of Chrysemys picta belli from southern Saskatchewan. Journal of Herpetology 15:181-185.

${ }^{13}$ McCOY, C. J. 1968. The development of melanism in an Oklahoma population of Chrysemys scripta elegans (Reptilia:Testudinidae). Proceedings, Oklahoma Academy of Sciences 47:84-87.

${ }^{14}$ MOLL, E. O., K. E. MATSON, and E. B. KREHBIEL. 1981. Sexual and seasonal dichromatism in the Asian river turtle Callagur borneoensis. Herpetologica 37:181-194.

${ }^{15}$ NORRIS, K. S. 1967. Color adaptation of desert reptiles and its thermal relationsihps. in Lizard Ecology: A Symposium, W.W. Milstead, editor. University of Missouri Press, Columbia. pp. 169-229. 
${ }^{16}$ PAPAGEORGIS, C. 1975. Mimicry in Neotropical butterflies. American Scientist 63:522-532.

${ }^{17}$ PRITCHARD, P. C. 1979. Encyclopedia of Turtles. T.F.H. Publications. 895 pp.

${ }^{18}$ SCHUELER, F.W. 1975. Notes on garter snake (Thamnophis sirtalis) spring mortality and behaviour at Long Point, Ontario. Ontario Field-Biologist 29:45-49.

${ }^{19}$ SCHUELER, F. W. 1979. Geographic variation in skin pigmentation and dermal glands in the Northern Leopard Frog, Rana pipiens. Ph.D. thesis, University of Toronto. $273 \mathrm{pp}$. (Dissertation Abstracts International 40B:5576, also Publications in Zoology, National Museum of Natural Sciences 16:1-80).

${ }^{20}$ SMITH, H. M., D. C. KRITSKY, and R. C. HOLLAND. 1969. Reticulate melanism in the Painted Turtle. Journal of Herpetology 3:173-176.

${ }^{21}$ THACKER, T. L. 1924. Notes on Bell's Painted Turtles (Chrysemys picta bellii) in British Columbia. Canadian FieldNaturalist 39:164-167.

22 WEBB, R. G. 1962. North American Recent soft-shelled turtles (Family Trionychidae). University of Kansas Publications, Museum of Natural History 13:429-611.

${ }^{23}$ YORKE, B. J., and G. R. KENDALL. 1972. Daily Bright Sunshine 1941-1970. Atmospheric Environment Service, Dept. of the Environment, Canada. CLI-672:1-7.

Appendix: Some evidence that Chrysemys picta is energy-coloured.

W. J. Hamilton III introduced the term "energy coloration" to describe colorations which reflect or absorb light to optimize the temperature of the organism. ${ }^{10}$ Both light and dark energy coloration have been invoked to explain the colours of reptiles. Snakes and lizards living on islands and peninsulas are frequently melanic and are thought to be energy-coloured black, and "superlight" coloration of heliothermic lizards is far more reflective than that of their backgrounds and is thought to prolong their surface activity in hot conditions. ${ }^{8}{ }^{15}$ It is supposed that up to the point that it is driven to a cool refuge by radiant heat loading, it is advantageous to an animal to be dark to maximize its metabolic rate, but if overheating often drives individuals into refuges it is beneficial to be light in colour and remain active at optimal temperatures for a longer period. ${ }^{10}$

I base the hypothesis that the coloration of C. picta is influenced by energy exchange considerations both on large-scale geographic variation and on the observation that among populations of $C$. picta examined in British Columbia, specimens from Texada Island were the lightest in colour, while those from across Malaspiza Strait at Pender Harbour were the darkest. ${ }^{11}$

The geography of Pender Harbour and Texada Island suggests that these sites differ in cloudiness. Northern Texada Island (where the lakes inhabited by turtles are found) is low enough that it does not cause much cloudiness by adiabatic cooling: the lakes are below $150 \mathrm{~m}$ elevation, and the highest points do not reach $460 \mathrm{~m}$. Pender Harbour is sandwiched between the $730-880$ $\mathrm{m}$ south end of Texada Island $20 \mathrm{~km}$ to the west and the $1250 \mathrm{~m}$ peaks of the Coast Range $7.5 \mathrm{~km}$ to the east. Among $101 \mathrm{ESSA}$ satellite weather photographs of western North America taken from April through 1 October 1974 there were 46 in which cloudiness of northern Texada Island and the Pender Harbour area seemed to differ (these observations strain the limits of resolution of the photographs): in 37 cases Pender Harbour was cloudier. Similarly, at the Strait of Georgia at Vancouver Airport there are 1244 hours of bright sunlight from May to September; 146 more than at Vancouver "P.M.O." $12 \mathrm{~km}$ to the north (S of Stanley Park; North Vancouver, at the foot of the mountains another $6 \mathrm{~km} \mathrm{~N}$, is well-known locally to be even cloudier), so that Vancouver Airport has as many hours of bright sunshine as stations in the prairies (Regina, 1348; Saskatoon, 1401; Brandon, 1231). ${ }^{23}$ । conclude that the environmental differences between Pender Harbour and Texada Island are likely such that the availability of sunshine is a major difference between the sites, and that an energy coloration explanation of the colour differences between the turtle populations is supported. It would be very interesting to know if turtles from either of these populations are reticulately melanic. 